\section{Apolipoprotein J}

K. J. Lackner ${ }^{1}$ und D. Peetz ${ }^{2}$

${ }^{1}$ Institut für Klinische Chemie und Laboratoriumsmedizin, Universitätsmedizin Mainz, Mainz, Deutschland

${ }^{2}$ Institut für Labormedizin, Helios Klinikum Berlin-Buch, Berlin, Deutschland

Synonym(e) ApoJ; Clusterin; Complement-associated protein SP-40,40

Englischer Begriff apolipoprotein J; clusterin

Definition Sekretorisches Protein, das u. a. in der $>$ High Density Lipoprotein-Fraktion gefunden wird.

Beschreibung ApoJ ist ein ca. $75-80 \mathrm{kDa}$ heterodimeres Glykoprotein, das als 449 Aminosäuren langes Proprotein nahezu ubiquitär synthetisiert wird und in fast allen Körper- flüssigkeiten gefunden wird. Kotranslational wird ein 22 Aminosäuren langes Propeptid abgespalten. Die verbleibende Peptidkette wird nach Aminosäure 227 in eine $\alpha$ - und $\beta$-Kette gespalten, die über eine Disulfidbrücke gegenläufig kovalent verknüpft sind. Viele Funktionen von ApoJ werden diskutiert, die meist mit Zytoprotektion zusammenhängen. ApoJ/Clusterin wird u. a. von Prostatakarzinomzellen unter Behandlung mit Docetaxel produziert, was zu einer Resistenz gegenüber dieser Substanz führt. Ob ApoJ/Clusterin diagnostische Relevanz in der Tumortherapie erlangt, bleibt abzuwarten

\section{Literatur}

Jones SE, Jomary C (2002) Clusterin. Int J Biochem Cell Biol $34: 427-431$

Magadoux L, Isambert N, Plenchette S et al (2014) Emerging targets to monitor and overcome docetaxel resistance in castration resistant prostate cancer. Int J Oncol 45:919-928 